\title{
Academic Learners in Finland: The Experiences and Perceptions of First- Generation Migrant Family Students in Higher Education
}

\author{
Golaleh Makrooni ${ }^{1}$ and Eero Ropo \\ Tampere University, Finland
}

\begin{abstract}
The increasing migration and internationalization of societies require a new dynamic architecture in higher education. Understanding the educational journey of specific groups of students is, therefore, of great importance. This study describes the educational pathways of first-generation migrant family students (FGMFSs) who have been successful in their university education. For this grounded theory study, fifteen FGMFSs at universities in Finland were interviewed. Three main categories - the academic environment, academic performance, and academic well-beingwere identified as critical factors influencing their educational success in higher education. The results of this study can help educators and policymakers better understand the factors that are important for FGMFSs' sense of belonging and educational success in higher education.

Keywords: academic environment, academic performance, academic well-being, first-generation migrant family students, grounded theory, higher education, Finland.
\end{abstract}

The importance of higher education in preparing students to work better and more efficiently in a society and its benefit to their private lives-socially, financially, and otherwise - are obvious (Hill et al., 2005). In this way, education should help to achieve socioeconomic advancement and reduce poverty. The United Nations (2017) validated these concepts by making high-quality education one of the 17 global goals for sustainable development. At the same time, the world is faced with corruption, wars, and poor governance. These conditions and the desire for a better life have led to migration worldwide. European Union (EU) countries are experiencing the effects of this migration. For example, thousands of children and young people with a migration background attend schools and universities in their host countries. However, the educational level that many have acquired when they enter their host country's educational system does not correspond to that of the local population. Great efforts are being made to understand better the challenges related to educating migrated young people and children, including scientific research activities in the social and educational fields. According to the academic achievements of migrant background populations across EU member states, "it is obvious that a 'one size fits all' approach to immigrant education in Europe would be far from efficient” (Bonin, 2017, p. 2). Airas et al.'s (2019) report on Finnish higher education students with an immigrant background supported this claim by demonstrating that these students are not provided with sufficient support during their post-secondary studies and Moitus et al.'s (2020) report on flexible pathway for students.

However, a segment of this population that has not received much attention is firstgeneration migrant family students (FGMFSs), higher education students who belong to migrant families, and whose parents do not have a university degree. In the context of higher education in Finland, few studies have focused on the experiences and perceptions of successful FGMFSs (Makrooni, 2019, 2020) compared to the US, where several studies have focused on

\footnotetext{
${ }^{1}$ Corresponding Author E-mail: Golaleh.makrooni@tuni.fi
} 
the first-generation college students (Ives \& Castillo-Montoya, 2020; Quinn et al., 2019). The topics have dealt with, for example, their persistence and completion of college studies (Holt \& Winter, 2018), and impact factors increasing the retention (Pellew, 2016).

This article aims to fill this gap in the literature by describing how FGMFSs experience and perceive their lives as academic learners in higher education in Finland. Taking a grounded theory (GT) approach, open questions were used to collect and analyze data, with sub-questions developed to investigate how FGMFSs' perceptions and experiences affect them as learners in higher education. This study provides data that lead to a better understanding of the educational situation, challenges, and factors that promote the success of college and university FGMFSs. The findings can help university teachers and administrators to formulate strategies and measures to secure and build on the successes of first-generation students with a migration family background.

\section{First-Generation Students in Higher Education}

A good body of literature about first-generation college students (FGCSs), with and without immigrant backgrounds, has been established, most of it emanating from the United States. The findings of these studies can be quite different from similar studies conducted in European countries like Finland, however, as the school and university systems of the different countries can often only be compared with great effort, for example, in the PISA studies.

Prior research on first-generation and non-first-generation students with a migrant or minority ethnic background has included examination and discussion on various topics, such as the difficulties and lack of support the students experience during their transition to college (Berggren et al., 2020) and their upper secondary education choices in Finland based on their attitudes about and experiences with the transition (Kalalahti et al., 2020). Other obstacles faced by these students identified in these studies include weak language and mathematics skills, inadequate study skills (Stebleton \& Soria, 2012), difficulty understanding the campus culture, and using campus facilities, such as libraries (Ilett, 2019).

The grade point average (GPA) is a significant predictor of resilience (Mendez \& Baumann, 2018), and the lack of peer support has been shown to be an indicator of lower GPAs (Dennis et al., 2005). According to Forrest Cataldi et al. (2018), first-generation students lag behind second-generation students in terms of persistence and success. Horowitz (2017) pointed out that this first generation "often work harder, are more motivated, engaged and determined than students of the second generation" (p. 9). Studies on self-efficacy also have shown interesting results. For example, Vuong et al. (2010) found that self-efficacy can impact GPA and persistence, while Chemers et al. (2001) reported academic self-efficacy and optimism could positively affect performance and adaptation; Ramos-Sanchez and Nichols (2007) revealed self-efficacy affects academic performance, college adaptation, and persistence of FGCSs. According to Meeuwisse et al. (2010), good formal relations with teachers positively impacted the sense of belonging of ethnic minority students, while Jeynes' (2003) meta-study showed the influence of parental involvement on all academic variables. Baum and Flores (2011) found that these students lacked information on access to funding, and Amos (2010) pointed out that it is not known which academic routes in university education had the greatest influence on the persistence of this population in the first two years. Emotional factors, such as well-being and loneliness (Neto \& Wilks, 2017), well-being and acculturation (Schwartz et al., 2013), depression (Stebleton \& Soria, 2012), and fear of failing (Bui, 2002) were also investigated, helping to gain a better understanding of the situation in which some of these students find themselves when attending college. Research on higher education students with an immigrant background in Finland has also identified problems like linguistic difficulties (Airas et al., 2019). These wide-ranging topics have been investigated, especially in the United States, to pursue data to inform strategies and program development to minimize dropout rates. 
However, knowledge specifically on the experiences and perceptions of FGMFSs as learners in higher education is lacking (Ives \& Castillo-Montoya, 2020); the literature mainly focuses on the struggles and adverse outcomes of FGCSs, while few studies have focused on the experiences of successful students in this population (Demetriou et al., 2017) or examined the factors that promote their academic success in Finland. Makrooni (2019) described the perceptions and experiences of FGMFSs as they travel the educational path to higher education in Finland, using three main categories: family values, institutional values, and friendship. A better understanding of the life of the FGCS and their learning experiences is also important for the faculties in order to better shape their overall learning experience at the universities (Delima, 2019) and to develop teaching strategies by strengthening the link between academic content and students' lives (Castillo-Montoya, 2019).

The current article focuses on the perceptions and experiences of FGMFSs while enrolled at higher education in Finland. Therefore, the main research question in this article is how FGMFSs experienced and perceived their educational careers in higher education relevant to their migration background. The results can provide a basis for educators and policymakers to improve the quality of educational institutions further and to promote the creation of an inclusive environment from school to higher education for FGMFSs.

\section{Positionality}

For additional context the first author shares her positionality in relation to this study. I myself studied and taught at school in a multicultural country with different languages and ethnics. My ethnic and cultural background and my experiences during my study and teaching awakened my interest in the cultural and social aspects of education and their role in shaping the educational journey. Gradually I became aware of the facts that these educational paths may differ due to family, ethnic, cultural and gender-specific backgrounds. I wanted to learn more about this topic and went on an educational journey myself. I had the opportunity to study this phenomenon in Finland. In Finland I was able to analyse the educational journeys of students with different ethnic and cultural backgrounds and to learn about what aspects that made their educational journey successful in an educational system that was foreign to their parents and to them. Moreover, the question of how this journey can be accompanied and supported even better by the educational system aims of great interest to me.

\section{Method and Data Sources}

This study applied the GT research method that Glaser and Strauss (1967) developed. GT not only elicits descriptions of experiences but also generates a theory for a process or an action to make it applicable in practice. The basic idea is that theories are grounded in the data that are systematically collected, such as actions and social processes in the interaction processes (Glaser \& Strauss, 1967). It was then further developed (Creswell \& Poth, 2018) individually by Glaser (2002) and Corbin and Strauss (2007) in differentiation from each other and later differentiated by their "students" - especially Charmaz (2006) with the constructivist grounded theory approach and Clarke (2009) with the situational analysis approach. However, the characteristic basic considerations of the grounded theory methodology are consistent despite many further developments. This includes above all the continuous alternation of fieldwork (data collection) and reflection (data analysis and theory building). Its essential features include conceptualization, permanent comparison, theoretical sampling and memo writing.

The field of research is considered to be without bias and prejudice. "The researcher enters the field and explores a substantive area by allowing the chief concerns of those actively 
engaged therein to guide the emergence of a core issue or problem" (Holton \& Walsh, 2017, p. 30). The study presented in this article employed GT to uncover unknown latent patterns in the academic lives of the FGMFSs. For this purpose, the participants were asked about their experiences and perceptions of university. According to Ribeiro (2014), "A comprehensive and faithful description of human perceptual experience has to consider, simultaneously, general, structural, individual, and situational elements involved in perception" (p. 561). For this research, perception is defined as the result of interactions between aspects of the individual (FGMFS) experience and context (university).

To ensure the reliability as well as the validity of data within a study, Morse et al., (2002) recommend different verification strategies. These include "methodological coherence, sampling sufficiency, developing a dynamic relationship between sampling, data collection and analysis, thinking theoretically, and theory development" (p. 18). These basic strategies are well founded and comprehensible. Within the framework of the GT, validity is based on the "interchangeability of indicators in multiple incidents" (Holton \& Walsh, 2017, p. 79). This is achieved by the "method" of comparative analysis of the initial data, the resulting concepts, which in turn lead to categories. One way to check validity, according to Creswell and Poth (2018), is to obtain feedback by reviewing by the participants themselves in order to allow the participants to check the data analysis. For this study, for example some transcriptions were randomly selected and sent back in order to allow participants to give feedback on the transcription. This was done to increase credibility and to avoid misunderstandings. They were also asked additional questions if there were discrepancies in the transcriptions.

\section{Data Collection}

Announcements about the study were posted in Spring 2017 on the university's Intranet website, faculty web pages, and Facebook page and the registration office and/or sent directly to students to recruit participants. Five students responded, three of whom were FGMFSs. The remaining 12 students in the study sample were found using the snowball method lasting about one year. Of the 15 total participating students, 8 were female, and 7 were male; their ages ranged from 25 to 38. Eleven participants came from the Middle East (Iran, Iraq), two from Central Africa, one from Russia, and one from Southeast Asia. The age of the participants when they immigrated to Finland varied. One was born in Finland, four relocated at the age of 1-5 years, three at 10-13 years, and seven at 16-18 years. Participants for this study were mostly (73\%) enrolled at the second largest university in Finland and studying social and human sciences, medicine, engineering, and natural sciences.

Collecting data proceeded from May 2017 to September 2018. The data were gathered through interviews, which lasted 90 to 110 minutes. All interviews were audio-recorded and then transcribed. Three interviews were conducted in the student's mother tongue, and the rest in English. The participants received the necessary information about the research objective, their rights, and the anonymous use of the data. Data were collected following the GT procedure in that no attempt was made to verify a pre-existing hypothesis. The data formed the basis for developing a grounded theory (Rupsiene \& Pranskuniene, 2010).

The theoretical saturation was considered (Holton \& Walsh, 2017), as no further insights into the research subject were gained after the 15 interviews were conducted. The number of data required for saturation is given as 10-15 in the relevant literature, depending also on the complexity of the study (Aldiabat \& Le Navenec, 2018). The theoretical saturation was achieved in this study after 15 interviews. New concepts or other significant data did not reappear (Holton \& Walsh, 2017). After the 10th interview it became apparent that no further new key issues were discovered, however, 5 more interviews were conducted to ensure that data saturation was achieved. Further data was not collected as the concepts and categories were 
saturated and a theory had emerged. Continuous comparison and memo writing also helped to reach saturation.

Interviewees were asked open questions that focused on the students' experiences and perceptions throughout their educational careers in higher education relevant to their migration background. For example: "What feelings did you have when you entered the university?" "What experiences did you have with staff, lecturers, and friends?" "How did you experience your studies at the university?" "What challenges did you experience, and what strategy did you use to deal with these challenges?" "What did you learn during your studies at the university?" "What suggestions do you have for other FGMFSs to help them academically succeed?" "What would you suggest that universities do in the future to help other FGMFSs to be successful?"

The data collection process was accompanied by the preparation of memos for the consolidation of the GT to serve as a basis for the subsequent interviews. The memos constituted the starting point for further sub-questions designed to gather more detailed information about the participants' experiences and perceptions of learning and living at the university, the obstacles they had to overcome, and the factors that helped them complete their studies successfully.

In addition to the advantages of GT in discovering unknown patterns in the educational pathways of this specific group in Finland, the authors are also aware of the limitations and challenges of using this method. The application of GT requires sufficient experience in data collection and analysis, which could be a challenge for a naive researcher and the possibility of errors is high. The sample size and data collection, the analysis of the data could also depend on the influence of the researcher's experience and background.

\section{Data Analysis}

An open, axial, and selective coding process was performed for data analysis (Strauss $\&$ Corbin, 1994). Open coding was used to find concepts and key phrases and to decompose the data into conceptual components. This coding enabled a better reflection on the data. In addition, all data were continually compared with each other in an attempt to identify similarities. This approach to coding generates ideas and establishes conceptual links between the main components and categories of what emerges (Holton \& Walsh, 2017). Selective coding was used to integrate the main categories. The different types of coding in the form of a continuous process were integral to the conceptualization of the perceptions and experiences of the participating FGMFSs. This process included discovering the properties of the respective categories and developing the relationships between them (Holton \& Walsh, 2017).

To exemplify the coding process, one interviewee pointed out that "to be successful depends on how much a human believes in himself and his abilities ... his interest in doing what he wants to do ... and how much they are ready to do that..." (see Table 2, A10a). Open coding produced "believing in self," "interest," and "having goals," and axial coding produced "self-belief," and "self-efficacy."

\section{Research Findings}

The participants' experiences and perceptions of their higher education were classified into three main categories: academic environment, academic performance, and academic wellbeing. These categories refer to what the FGMFSs perceived and experienced during their time at the university, explain the essential aspects of success at the university, and indicate improvements needed in Finnish higher education and what proved to be useful for this group of students. The categories overlap in some respects. For example, research shows that a high 
degree of self-efficacy is associated with good performance, but a high degree of self-efficacy is also associated with feeling good. Therefore, individual sub-categories like self-efficacy appear in several main categories.

\section{Academic Environment}

To be an FGMFS often means being the first in the family to obtain a higher education degree. For these students, the organization and requirements are new, and the wishes and hopes are great. The gateway to a better life in the future through access to knowledge has been reached. As FGMFSs are the often first in their family to go to university, they receive no specific instructions from parents and siblings regarding what to expect or how to handle challenges and have no one in their close family environment to turn to for advice on such matters. Thus, they encounter the academic environment with a degree of uncertainty about what to expect. Through the coding process, the following axial key codes related to the participants' experiences and perceptions of the academic environment were created: the challenge of the academic language, Finnish as a second language, and getting to know academic writing (e.g., essay writing and reflective writing). The code of academic working included different academic skills, such as autonomy, which pertains to being in charge of one's action, reflecting on feedback to improve; critical thinking and questioning; and discussion and group work. Additional axial codes included the following: academic institutional norms and rules at the university; teaching behaviors and student-teacher relationships; integration into seminars; teaching methods; organizational structure; and university-based cultural offerings and support. All sub-categories characterize the university as an institution and comprise fundamental elements of university culture. The main findings in this category are discussed according to three subtopics: academic work (requirements from the university), academic relationship (teacher-student), and academic climate (university-based offerings and impact on students' thinking).

1.1 Academic work. The participants' perceptions and experiences regarding their studies and the challenges they faced while in university resulted in the academic work subcategory. The students noted that the lack of behavioral practices and skills needed for the academic work presented significant obstacles. For example, their language skills were challenged on very different levels, including the academic language used in the different disciplines and by different faculties (Table 1.1, A10). The Finnish language had always presented a challenge for many, as the majority (73\%) of the students interviewed moved to Finland as teenagers; however, they realized that the demands on their language skills were even higher while studying at the university than they had been in high school (Table 1.1, A5). They pointed out that Finnish teachers and Finnish students never embarrassed or corrected them in front of the class for incorrect use of the language, which was a criticism of other places (Table 1.1, A15).

Most $(n=8)$ also found academic writing highly challenging: they perceived it as very difficult and required more effort on their parts because Finnish was not their mother tongue (Table 1.1, A4, A8). However, three participants recounted having had no problems with academic writing, one even possessing advanced skills (Table 1.1, A14). Specific study skills, such as analytical skills, independent and autonomous learning abilities, argumentation, and critical thinking, are also necessary to succeed in higher education. The students noted that the need for these skills presented further obstacles to their success (Table 1.1, A15a), as they found the way of thinking and work habits of their peers at the university quite different from those of the friends they had before university (Table1.1, A6). They reported feelings of "shock" early in their university studies at the amount of responsibility that was placed on them for their own learning compared to what they experienced in high school), where teachers provided more 
support, and finding it difficult to adjust to this shift (Table 1.1, A7). Table 1.1 includes interviewee quotations related to academic work.

\section{Table 1.1}

\begin{tabular}{|c|c|}
\hline Interviewee & Quotation \\
\hline A4 & $\begin{array}{l}\text { "Speaking is easy; writing is much more difficult because Finnish is not my mother tongue ... } \\
\text { knowing some technical words is easy for [native-speaking] Finnish, but I had to work to } \\
\text { understand better." }\end{array}$ \\
\hline A5 & $\begin{array}{l}\text { "It was very different, the materials that we had in university were instantly much harder and } \\
\text { we did not ever have it at high school and ... texts with super scientific terms... because } \\
\text { scientifically language is really difficult and that is something's that you did not study at } \\
\text { schools because not everyone will use it." }\end{array}$ \\
\hline A6 & $\begin{array}{l}\text { "[The] university was a really different environment, and people were different in their way of } \\
\text { thinking. At [the] university, my friends and their parents were highly educated, and their way } \\
\text { of thinking and their knowledge was not comparable with [that of] my friends before } \\
\text { university.... They had a different world in comparison with those friends that I had before } \\
\text { going to [the] university." }\end{array}$ \\
\hline A7 & $\begin{array}{l}\text { "There is a lot of responsibility for the student herself or himself to study and learn, whereas } \\
\text { when you are in school, the teachers take a lot of responsibility for you... But at [the] } \\
\text { university ... you have to be aware of everything and take a lot of responsibility, so that was } \\
\text { very shocking for me." }\end{array}$ \\
\hline A8 & $\begin{array}{l}\text { "Writing was too hard for me. I was never a good writer, and it was very difficult for me to } \\
\text { write essays or to do some homework [assignments]. My grammar was not my problem. I } \\
\text { learned it quickly at first, and I do not have difficulty writing correctly, but academic writing } \\
\text { was a problem." }\end{array}$ \\
\hline A10 & $\begin{array}{l}\text { "In the first days and first semesters, the teachers, for example, talked about power, voltage, } \\
\text { and some expressions related to electricity. I did not understand anything, and you know all } \\
\text { lectures were in Finnish." }\end{array}$ \\
\hline A14 & $\begin{array}{l}\text { "I never had these kinds of linguistic problems with writing or stuff ... because I have written } \\
\text { so much you know; I even wrote in magazines and books." }\end{array}$ \\
\hline A15 & $\begin{array}{l}\text { "Finnish people never break your face [embarrass you], ... they do not mention it that you are } \\
\text { talking wrong.... I would like them to correct my Finnish language, but they do not." }\end{array}$ \\
\hline A15a & $\begin{array}{l}\text { "There are many things at [the] university that you feel alien to,... [no] person that gives you } \\
\text { guidelines or shows you what to do, and you are in the place where everyone is thinking } \\
\text { differently." }\end{array}$ \\
\hline
\end{tabular}

1.2 Academic relationship: Teacher-student. The relationship students have with their professors or teachers, in reference to the axial coding, can be described in terms of support, interest, and feedback. Some $(n=4)$ had very positive experiences (Table 1.2, A2), but some $(n=4)$ complained about a lack of support (Table 1.2, A7, A8), while a couple $(n=2)$ reported objecting to negative feedback they received in terms of language (Table 1.2, A3). Overall, students indicated that they would like more support from and interactions with faculty. The participants' views about feedback, support, and relationships with teachers seemed to depend on the faculty and the course being taught. For example, students noted that they had too little interaction with their technical subject teachers (Table 1.2, A7a).

The interviewees pointed out that the professors demonstrated a high degree of equality in dealing with students, explaining that they were not treated differently because of their origin (Table 1.2, A13). According to participants' feedback, teachers had no interest in who students were: the subject was in the foreground, not the person or his or her country of origin (Table 1.2, A12). However, they opined that the teachers should give more consideration to students' migration backgrounds and difficulties with the language (Table 1.2, A10). The interviewees mentioned that more opportunities should be available for students to ask for support. The expectation of students to take responsibility for their learning and organization of their studies was mentioned again (Table 1.2, A11). 
Moreover, a contradiction became apparent in the analysis of the interview data. On the one hand, the students expressed a desire to receive more individual help and feedback. However, this would result in their being treated differently, which is contrary to the principle of equality, a highly valued doctrine in Finnish society. Thus, this situation reflects a contradiction in goals because if all are treated equally, injustice can occur, but if all are treated fairly, inequality can occur. Table 1.2 contains interviewee quotations about the teacher-student relationship.

\section{Table 1.2}

\begin{tabular}{|c|c|}
\hline Interview & Quotation \\
\hline $\mathrm{A} 2$ & $\begin{array}{l}\text { "Positive feedback [from my teacher on an essay] ... gave me courage ... it makes you more } \\
\text { confident that you are at the same level as everyone else." }\end{array}$ \\
\hline A3 & $\begin{array}{l}\text { "Just one bad experience, one ... teacher told me he was very surprised that ... [someone] } \\
\text { allowed me to enter the university ... 'your language is not good [enough] ... to study at [the] } \\
\text { university.' ... He [later] apologized to me." }\end{array}$ \\
\hline A7 & $\begin{array}{l}\text { "I do not know how to do [the work in] this course. The questions are difficult; the teachers } \\
\text { are not helping me, [and] I do not have any friends at the university to help me. My friends } \\
\ldots \text { do not know anything about this, and they are cooking pizza, so I cannot go there and ask } \\
\text { them. So, you become hopeless." }\end{array}$ \\
\hline A7a & $\begin{array}{l}\text { "They [teachers] come and teach, and then they go; they are not interested if you are listening } \\
\text { or if you are learning.... In large-sized classrooms, they just show some slideshows.... If you } \\
\text { are studying engineering, nobody wants to discuss-just give a lecture and go ... in big classes } \\
\text { you cannot ask [questions]." }\end{array}$ \\
\hline A8 & $\begin{array}{l}\text { "In my short absence [from attending] the university, teachers asked about my absence, but } \\
\text { when they saw me somewhere ... nobody offered any help actually." }\end{array}$ \\
\hline A10 & $\begin{array}{l}\text { "Teachers [should give you the] ... feeling that if you have a problem in [understanding the] } \\
\text { language, you can ask ... then it could be easier for these students to ask [for help]... } \\
\text { Sometimes being in seminars creates the most stress for me, and it happens even if I know } \\
\text { that I can speak ... and I think it is because teachers did not give the impression that it is not } \\
\text { a problem for you to make mistakes." }\end{array}$ \\
\hline A11 & $\begin{array}{l}\text { "[The] university is a totally different world from high school ... at the university, you are on } \\
\text { your own.... They only show you some stuff ... nobody is going to help you. Teachers drown } \\
\text { new students in an ocean of knowledge." }\end{array}$ \\
\hline A12 & $\begin{array}{l}\text { "As I told you, I had the impression that teachers are not interested in who I am and where I } \\
\text { am from. They do not know [that you are an immigrant] probably, and they do not ask." }\end{array}$ \\
\hline A13 & $\begin{array}{l}\text { "I have not realized differences from my classmates [in the way we are treated] by professors } \\
\text { and teachers. They try not to treat you differently, not in a positive or negative way. They } \\
\text { required the same thing from students ... they will never start ... discussions [or ask } \\
\text { questions]...They do not show interest at first, ... you have to bring it [up] yourself so that } \\
\text { they will ask you more ... but I never felt that my background made them do something } \\
\text { differently." }\end{array}$ \\
\hline
\end{tabular}

1.3 Academic climate. The academic climate in this context refers to the quality and character of university life, which encompasses students, staff, cultural offerings, values, and organizational structures. When asked about their experiences with the university's cultural offerings or activities specifically, most recalled never having experienced any. Of those who had, some referred to a special seminar or course (Table 1.3, A3), and others mentioned activities outside the university (Table 1.3, A14). Two participants also spoke about their shyness and feelings of shame in standing up for and openly displaying their culture (Table 1.3, A5) but added that they liked to talk about their culture when someone asked about it. Overall, most pointed to the lack of courses and programs targeted at FGMFSs at their university. Some assumed only limited offerings were available because the population of students with migrant backgrounds was small and because no one requested such programming (Table 1.3, A10).

The interviewees noted they viewed their overall higher education experience positively, including the outcomes of increasing their knowledge and becoming more open- 
minded (Table 1.3, A3a). They learned to observe the world through different lenses and gained an understanding of the values that residents of Finland and the rest of the world held (Table 1.3, A4), which they explained was helpful for integration (Table 1.3, A6). They described the atmosphere at their university as one in which everyone was treated equally, and no racism was witnessed (Table 1.3, A7); for some, it was the first time experiencing such a climate (Table 1.3, A6a). Students commented others were not concerned with who one's parents were other than to ensure the student received support from the family and the wish that more migrants went to the university to study. The interviewees pointed out that such an academic environment provides a setting for efficient and successful learning (Table 1.3, A13). They also expressed appreciation for the equal treatment and open-mindedness they experienced. Table 1.3 presents the quotations of interviewees related to the academic climate.

\section{Table 1.3}

\begin{tabular}{|c|c|}
\hline Interview & Quotation \\
\hline A3 & $\begin{array}{l}\text { "Yes, I had one experience in one seminar among our classmates in our major when I wore my } \\
\text { traditional cloth ... and also talked about my culture, and they liked that." }\end{array}$ \\
\hline A3a & $\begin{array}{l}\text { "A university education helps you develop your character... Studying at [a] university teaches } \\
\text { you many things...I increased my knowledge, and it helped me to be open-minded." }\end{array}$ \\
\hline A4 & $\begin{array}{l}\text { "You could see the world from different views, maybe understand much better the life values } \\
\text { here in Finland and the world." }\end{array}$ \\
\hline A5 & $\begin{array}{l}\text { "It is a shame, really, because my other friends do not (do) really anything like that.... If you are } \\
\text { the only one [going to university], that makes you feel lonely, too." }\end{array}$ \\
\hline A6 & $\begin{array}{l}\text { "The university [climate] is helpful in many aspects, for example, for integration, humanity, } \\
\text { serious things, and broader issues." }\end{array}$ \\
\hline A6a & $\begin{array}{l}\text { "In university, others did not see you as a foreigner; they do not pay attention to that, and the } \\
\text { atmosphere is that everyone is the same. In high school, they see that you are different and tell } \\
\text { you that you are different." }\end{array}$ \\
\hline A7 & $\begin{array}{l}\text { "When I came to the university, it was a totally different situation [from what I was used to]; } \\
\text { there was no racism because people are well-educated, and the mindset had been changed." }\end{array}$ \\
\hline A10 & $\begin{array}{l}\text { "I would like to introduce my culture and talk about these things ..., but I [only] talk if someone } \\
\text { asks me.... I never had such cultural programs. None of my teachers or classmates ever asked } \\
\text { me about where I am from." }\end{array}$ \\
\hline A13 & $\begin{array}{l}\text { "I am in an environment where I can work hard and achieve these things. If I were in another } \\
\text { environment, I might not have these things. So, environment, society, and everything from the } \\
\text { culture that surrounds you are effective." }\end{array}$ \\
\hline A14 & $\begin{array}{l}\text { "I do cultural, social activities all the time, but I didn't do it at the university level ... I am doing } \\
\text { this on a society level." }\end{array}$ \\
\hline
\end{tabular}

\section{Academic Performance}

In the category pertaining to the strategies participants employed to manage their studies successfully, open coding and axial coding resulted in the following important axial key codes: self-reflection and self-discovery, different perspectives and thinking, perfectionism versus letting things go, persistent and hard-working, motivation, self-efficacy, and attitude toward work. In addition to the many experiences and challenges that arise from immersing oneself in a new environment, the FGMFS as a learner with his or her own experiences is at the center of these categories.

Naturally, this category overlaps with the academic environment category and with well-being, but it became clear when analyzing the interview data that students' self-concepts were essential to their ability to be successful in the learning process. An impressive aspect of their experiences and perceptions was the examination of self. The interviewees expressed that they had learned to think for themselves and to identify the appropriate methods for accomplishing tasks (Table 2, A4); they learned to understand their abilities better and discover 
who they were, believe in themselves, and be themselves (Table 2, A2, A9), and to take responsibility for their thinking. They also recounted learning not to compare themselves with the Finns in terms of language skills. They noted that among the most important lessons their post-secondary education taught them was to question everything, to understand different perspectives (Table 2, A13), and to not only set but be persistent in achieving goals by not giving up when faced with obstacles but, instead, working to overcome them (Table 2, A15).

Table 2

\begin{tabular}{|c|c|}
\hline Interview & Quotation \\
\hline A1 & $\begin{array}{l}\text { "I did not like to give up.... I believed [in] myself, there was, like, hope that I will be able to } \\
\text { overcome it." }\end{array}$ \\
\hline A2 & $\begin{array}{l}\text { "Maybe the biggest thing ... I have learned in university is believing in myself.... If I want to do } \\
\text { something, I can do it, and it's not hard if I want to do it-I just have to work for it." }\end{array}$ \\
\hline A4 & $\begin{array}{l}\text { "I learned ... what will be a solution or what can I do to be better... I just encouraged myself, or } \\
\text { I told myself that maybe I could do something in a different way and work harder, and I do not } \\
\text { give up on myself ... and I did it, and I felt I got better." }\end{array}$ \\
\hline A5 & $\begin{array}{l}\text { "In the group we got texts, and we were reading texts together and asking each other, 'did you } \\
\text { get that part?' because sometimes what I got [from the message] was different than what they } \\
\text { said, and it was really good to get kind of different pictures." }\end{array}$ \\
\hline A6 & $\begin{array}{l}\text { "It was strange and ... hard at first, ... the style of studying was strange ... spending eight hours } \\
\text { a day just doing homework ..., but I got used to it." }\end{array}$ \\
\hline A8 & $\begin{array}{l}\text { "Reading and academic writing was not my [strength] ... I was never a good writer, and it was } \\
\text { very difficult for me to write essays or to do some homework [assignments] ... so I stopped and } \\
\text { for half a year I just thought about that-why, really, do I want to do that? And after a half year, } \\
\text { I thought, I have to work harder ... I had to believe in me that I can make it." }\end{array}$ \\
\hline A9 & $\begin{array}{l}\text { "I understood my abilities better... university helped me to think again about myself ... to know } \\
\text { myself ... to find myself again ... my self-confidence increased." }\end{array}$ \\
\hline A9a & $\begin{array}{l}\text { "I understood that I should indicate my plan for my life and achieve my goals step by step.... I } \\
\text { think my efforts and my standing on my purpose is the secret of my success." }\end{array}$ \\
\hline A10 & $\begin{array}{l}\text { "I tried to find a way for more understanding of the subjects ... I searched the Internet ... read } \\
\text { the books in these languages that I knew [mother and native], and I just tried by myself." }\end{array}$ \\
\hline A10a & $\begin{array}{l}\text { "To be successful depends on how much a human believes in himself and his abilities ... his } \\
\text { interest in doing what he wants to do ... and how much they are ready to do that." }\end{array}$ \\
\hline A12 & $\begin{array}{l}\text { "In case of language their [Finnish students] study is much easier compare to me... although } \\
\text { language is a challenge for me but I do not take it as an excuse , and I do not take it like ok I am } \\
\text { lower than them" }\end{array}$ \\
\hline A13 & $\begin{array}{l}\text { "I learned to question everything while in school ... look at things from many different } \\
\text { perspectives ... not believing I had the absolute answer.... We discussed this in our courses a } \\
\text { lot." }\end{array}$ \\
\hline A13a & $\begin{array}{l}\text { "I think every time you put effort into something, and you work hard for it, and you achieve it, } \\
\text { you have been successful." }\end{array}$ \\
\hline A14 & $\begin{array}{l}\text { "I have very Finnish attitudes on life, like European.... I was humbled by the opportunity ... to } \\
\text { do this and that, and it is why I am different tomorrow [than today].... My attitude now is ... } \\
\text { don't have the victim mentality ... no matter what happens, you take the responsibility of } \\
\text { changing." }\end{array}$ \\
\hline A15 & $\begin{array}{l}\text { "Many times, I became sad ... regretted [going to university] and told myself it was finished ... } \\
\text { but I stood up and continued... You should believe in what you want and put away many things." }\end{array}$ \\
\hline
\end{tabular}

It was interesting that their university experience taught them they did not need to be perfect and not be too hard on themselves when things did not go their way. Of course, the students also learned to perform the necessary tasks and to meet the requirements involved. They learned to ask questions until they got the help they needed if they were unsure how to proceed with a certain task or assignment and observed that through this process, their skills improved, and they became more knowledgeable. They also discovered ways to ensure their difficulties with the language did not prevent them from achieving their objectives after realizing that focusing on the challenges the language barriers presented did not help them reach 
their goals (Table 2, A12). They explained that they just worked harder and motivated themselves when faced with obstacles (Table 2, A4), dedicating many hours, and much persistence (Table 2, A6). The interview data further revealed that, throughout their higher education experience, the students discovered that persistence was the secret to success (Table 2, A9a) and that hard work coupled with practice was the only way to achieve their academic goals (Table 2, A13a). That the students demonstrated a high degree of persistence and endurance while studying was evident from their comments; they refused to give up when presented with roadblocks to their success.

Another important sub-category that emerged for success was self-efficacy. This was expressed as believing in oneself and being able to succeed (Table 2, A1, A8, A10a). Being organized in groups or learning together was emphasized (Table 2, A5). Attitudes towards more responsibility, learning, and better work habits were also mentioned as important concepts for self-efficacy (Table 2, A14). This included also identifying the methods that best helped them to understand a topic better (Table 2, A10) and seeing difficulties such as those presented by the Finnish language as challenges but not problems. Participant comments regarding academic performance can be found in Table 2 .

\section{Academic Well-being}

The academic well-being category can be divided into three areas: psychological wellbeing (personal mastery, finding one's position, making decisions and setting goals, changing attitudes, feeling of how one is perceived, and the feeling of being different), emotional wellbeing (pride, happiness, fear, loneliness, helplessness, hopelessness, motivation, and otherness), and social well-being (friendship and interaction with others at the university). The students described experiencing overwhelming conflicting feelings at the beginning of their studies when they were finally at the university, the place where knowledge is imparted. They felt good and proud to be the first in the family or the first among friends to achieve this (Table 3, A8). All were happy to be in university and to start a new life, to start over, to leave the old behind, to have made it (Table 3, A1). They were happy, too, with the subjects they were studying $(n=$ 13). They were aware that attending university was a significant achievement for them, for their families, and other migrants. They did not give up; they overcame all obstacles that stood in their way and, in doing so, increased their motivation to succeed and to be a good role model for other immigrant students (Table 3, A13). However, pride and happiness were not the only feelings recalled; participants also recounted feelings of fear and stress (Table 3, A15), helplessness (Table 3, A5), being alone, and, above all, loneliness ( $\mathrm{n}=7$; Table 3, A7), all caused by a lack of help and support. For two interviewees, the age difference was also mentioned as a reason for being alone.

The feeling of being different from the host society was also mentioned; they felt it brought attention to them, but this attention was not assessed negatively (Table 3, A2). Others pointed out they did not feel they were judged differently in terms of intelligence and performance or treated differently based on their ethnic origin (Table 3, A6). This also applied to their relationships with their teachers. Some had the feeling that teachers were proud of them. The teachers were considered friendly and did not treat them differently; however, for some, this created feelings of stress because they were expected to perform at the same level as other students (Table 3, A10).

Friendship with other committees also played an essential role in their well-being, according to the data. The importance of making new friends to be socially engaged and adjust to the new environment emerged through the interviews. For some, the new environment presented the opportunity to make new friends and maintain friendships with other students from their preparation courses, first joint courses, orientation courses, and continuing courses 
$(n=5)$. Some $(n=6)$ felt integrated, considered themselves social, had many friends from the beginning (Table 3, A12), and pointed to the mutual influence that took place between them, such as learning from each other (Table 3, A14). Others had difficulty making friends $(n=6)$ and felt they had to give up to be completely themselves and play a role (Table 3, A10a), while others pointed out that although they had tried in many ways to make friends, it was challenging to establish close friendships with Finns. For some, friendships only existed at the university and in the courses but did not continue outside the university environment (Table 3, A15a). All in all, the participants considered friendship a critical factor in their well-being and academic adjustment. The data further showed that the age of arrival in their host country (Finland) was indicative of having close friendships.

\section{Table 3}

\begin{tabular}{|c|c|}
\hline Interview & Quotation \\
\hline A1 & $\begin{array}{l}\text { "It's kind of like starting a new life, and like there was hope that everything would help me } \\
\text { find my place in society, and I would be ... happier in life." }\end{array}$ \\
\hline A2 & $\begin{array}{l}\text { "You always know that you are different because you look different from everyone else.... } \\
\text { Every time when you came to class, you get attention ... teachers always remember your } \\
\text { name first ..., but also I feel like everyone is nice." }\end{array}$ \\
\hline A5 & $\begin{array}{l}\text { "Sometimes, I felt proud [but] also sometimes helpless because there was no one in my family } \\
\text { to ask, so I would have to ask ... the teachers and staff." }\end{array}$ \\
\hline A6 & $\begin{array}{l}\text { "Actually, they [teachers] did not see me as different and as [having] a lower IQ or anything } \\
\text { like that. The only one that sees like that is us, and that is not reality." }\end{array}$ \\
\hline A7 & $\begin{array}{l}\text { "I was totally alone in the university, and the Finns were among themselves.... At some points } \\
\text { when I had some difficulties in some courses, there was nobody to help me or nobody to do } \\
\text { the problems with me, so at some points, you feel despair." }\end{array}$ \\
\hline A8 & $\begin{array}{l}\text { "I was very proud of myself... I don't know any immigrant men studying in my major here } \\
\text { at the university." }\end{array}$ \\
\hline A10 & $\begin{array}{l}\text { "I always had stress because they gave me this feeling that I do not have any differences with } \\
\text { Finns in the case of language... It is true that I do not want teachers to treat me separately } \\
\text { from others, but I feel it [would be] positive in this line that teachers know that I am not like } \\
\text { others, and it is not necessary to have as much stress to do [work at the same level] as Finnish } \\
\text { do." }\end{array}$ \\
\hline A10a & $\begin{array}{l}\text { "Sometimes, you should play a role (it means you should change your character apparently) } \\
\text { because if you want to be yourself, it will be difficult to integrate fully into the class." }\end{array}$ \\
\hline A12 & $\begin{array}{l}\text { "I think I am social, like, I can describe myself socially based on my life experiences.... I am } \\
\text { quite well integrated into the university that I can ask other students or teachers ... I have } \\
\text { some hobbies and activities with not just classmates..." }\end{array}$ \\
\hline A13 & $\begin{array}{l}\text { "I felt very proud because I wanted to achieve, and I achieved, and it was not very normal for } \\
\text { immigrants... I was the first to get to the university, and it was a big thing for my family... } \\
\text { and it creates a responsibility to do things well because it's like you are paving the path for } \\
\text { the next generation." }\end{array}$ \\
\hline A14 & $\begin{array}{l}\text { "I know they [friends] have impacted me, and I have impacted them. I was like, 'hey, listen, } \\
\text { listen' ... it is not very normal among Finns to say, 'hey listen, listen,' ... so everybody } \\
\text { learns." }\end{array}$ \\
\hline A15 & $\begin{array}{l}\text { "I could not enjoy myself really as I felt fear. I mean, I was afraid that maybe I could not do } \\
\text { that and study at university." }\end{array}$ \\
\hline A15a & $\begin{array}{l}\text { "To be honest, to be friends with the Finnish is not easy.... Our friendship is just about our } \\
\text { study inside the university ... it did not go further like to be with them outside the university." }\end{array}$ \\
\hline
\end{tabular}

\section{Discussion}

In this study, three categories emerged based on the GT analysis: academic environment, academic performance, and academic well-being. The academic environment includes all formal and informal aspects of an academic institution. Meeuwisse et al. (2010), in their model, assigned factors to formal and informal teacher interactions and formal and informal student interactions in the learning environment. In Tinto's (1993) model, a distinction 
was made between academic integration and social integration. Academic integration refers to the intellectual life of the university, while social integration refers to relationships and connections outside of the classroom. The academic environment is also shaped by learning models, such as the Biggs (1989) learning model, which assumes that it is the teacher's job to create a learning environment that supports learning activities that lead to achieving certain learning outcomes. This support involves aligning the curriculum, outcomes, teaching methods, and assessments, which he called constructive orientation. These models and concepts are applied to explain and understand the tasks and processes in academic institutions, such as dropping out, success, perseverance, student support, norms, and values.

In this study, academic environment refers to the sub-categories that the FGMFSs interviewed mainly experienced, which include academic abilities and skills, the interaction between teacher and students as well as between students and students, activities, programs, teaching methods, assessments, and assignments, teaching behaviors, institutional values, and university culture.

The process of integrating and understanding the institutional norms and requirements and becoming familiar with the university culture was highly challenging, according to the participants. The interviewees repeatedly referred to language skills in general as making these processes more difficult. A distinction can be made between academic language, technical language, and Finnish as a foreign language. The use of academic and technical language is part of university education and must be learned as core skills. What makes things even more difficult for some students pertaining to language skills is that in Finland it is also necessary for civil servants in public professional positions, such as lawyers, teachers, or doctors, to have a good knowledge of Swedish which is the second official language of the republic of Finland. This is one reason for the importance to include multilingual education in curricula to promote social justice (Paulsrud et al., 2020). Academic writing, which is another core academic skill and ability essential for academic life, constituted another significant challenge. However, the data indicated that the participants gradually improved their academic writing skills while pursuing their degree.

Overall, FGMFSs recommended that future FGMFSs pursuing an advanced degree take more courses to learn and improve their academic language skills. Further competencies and skills, such as independent learning that professors expect students to have, which the interviewees had considered themselves lacking in, need to be learned as well. The participants explained that to cope with the new norms, rules, and requirements of studying at a university, they needed time and space for the possibility to think, to adapt to them, and to find coping strategies. The adaptation and coping were needed due to their educational backgrounds, academic Finnish language skills, and cultural influences. The participants recalled often needing more time to ask themselves questions about the tasks, and to consider the areas in which they were experiencing difficulties, and to identify the proper actions to take and the appropriate process to follow when taking them to address those issues. These possibilities included group work when interacting with others, asking questions, responding to questions asked by teachers, and talking about feelings and thoughts. According to participants, no specific multicultural programs were offered, but the diverse and heterogeneous atmosphere, as mentioned previously, differed from the atmosphere of high school in a positive way, all under the umbrella of equality, which they highly appreciated. In their study, Zilliacus et al. (2017) confirmed the students' impression that only superficial multicultural programs have so far been established in education in Finland. However, new curriculum reforms are expected to integrate the multicultural perspective more strongly into education. Equal opportunities at the university were seen as positive and were highly valued by all of them. However, the value of equality conflicted with equity. Because of students' migration background, being treated equally could 
negatively impact equity because it may be unfair for students to be expected to complete tasks that require certain skills that they do not possess.

Interactions between teachers and students were reported as both appropriate and inappropriate, depending on the subject and the number of students in the class. Teachers were found to be helpful and supportive, especially in providing feedback. However, the students felt they would have benefited if the teachers had tried to learn more about the students and encouraged them to tell more about themselves. These interactions also reflect the students' level of involvement in the university. Involvement in the university, according to Tinto (1998), is an essential factor in students' perseverance.

The results pertaining to the second category, academic performance, show that FGMFSs applied their experiences and the challenges they encountered to develop into academic learners, successfully building their thinking, acting, and learning skills. They recognized these challenges, questioned themselves, and evaluated the situation. They saw the opportunities offered by studying at the university and understood that the only way to overcome the challenges was to work harder than others, to study more consistently and persistently, and not to give up. They changed their attitudes and thinking by believing in their goals and staying focused on what they wanted to achieve. These results are in line with the work of Dotson (2016), who argued that the correct formulation of objectives leads to improved student performance. They began to use what they learned from teachers, friends, and peers for their progress to become independent and stand on their own two feet. They realized that it was not easy for them to achieve their goals and that they had to change their attitude, their way of thinking, and the way tasks were done, so they worked to become more and more efficient. They all had a high degree of self-efficacy and perseverance. As found in other research (DeFreitas \& Rinn, 2013), there was a positive relation between academic self-concept and academic achievement for these students. Their self-confidence, hard work, motivation, and interest in the subject and discipline and the goal of remaining at the university led them to succeed.

These results are also in line with those related to the concepts of self-efficacy and persistence. Zimmermann (2000, p. 86) wrote, "Self-efficacy beliefs have also shown convergent validity in influencing such key indices of academic motivation as the choice of activities, level of effort, persistence, and emotional reactions." Martin and Marsh (2009, p. 353) defined academic resilience as "a student's ability to overcome acute or chronic adversities that are seen as major attacks on educational processes." The Conway (2009) model of immigrant and native student persistence includes high school preparation, resources for academic skills, and educational aspirations. In this model, she compared different groups, but the results were inconsistent. Individual student groups showed persistence in specific areas, while the vast majority of students at community colleges in the United States did not show persistence. It is obvious, however, that perseverance and hard work were a necessary condition for success.

With regard to perseverance, Mendez and Baumann (2018) investigated persistence in a College Assistant Migrant Program (CAMP) and were able to show that academic resilience in the Latinx student population was not associated with academic persistence. Instead, family responsibilities, work, and debt accumulation seemed to be the strongest predictors of leaving college in their circumstances. Edman and Brazil (2007) could only partially confirm their hypothesis that ethnic minority students have lower self-efficacy.

For the target group of the current research (FGMFSs), a high degree of self-efficacy and persistence of students was uncovered during the interviews, although the way this group of students studies seems to be a blind spot for universities. Universities seem to underestimate the challenges they face and how they manage and overcome these challenges. Lecturers and administrative staff should give more attention to the situation these students face and how they can receive more support. The experiences and perceptions of the FGMFSs in this study show 
that more support for the learning process is needed. Although this study highlights the strengths of these successful students, it is possible that not all FGMFSs work hard enough or have the strong persistence necessary to succeed.

The third category, academic well-being, consisted of psychological, emotional, and social aspects for coping, adapting, and functioning in life. For Gräbel (2017), psychological well-being referred to the purpose of life, personal growth, environmental mastery, selfacceptance, and autonomy, and social well-being referred to positive attitudes toward people as well as belief in the growth and understanding of society and participation and identification with the society; emotional well-being refers to positive and negative emotions. Diener (2006) focused on positive effects (e.g., contentment, pleasure, euphoria, interest, engagement, and joy) and adverse effects (e.g., sadness, anxiety, worry, stress, frustration, guilt and shame, envy, loneliness, and helplessness). These positive and negative emotions and moods play a major role in our daily lives. Bui (2002) discovered that first-generation students had a greater fear of failing in college. Gräbel (2017) found a positive relationship between emotional and psychological well-being and academic achievement. Cobo-Rendon et al. (2020) reported that mental health impacts the well-being and academic performance of academic learners.

These results align with the findings from the interviews in this study. The interviewees conveyed positive emotions, like pride, happiness, and overall positive feelings, but negative emotions, like loneliness, helplessness, and stress, were also mentioned The feeling of loneliness that was experienced had to do with the difficulty in making friends among Finns at the university. Having friends and studying with them as a group, not being alone, and getting support from peers was very important. Friends can help with academic adaptation, can share information, exchange academic experiences, and students encourage and learn from each other. Loneliness was also partly caused by significant differences in age (they felt too old, particularly if the age of arrival was 17 or 18, to make friends) or cultural differences (not going to pubs). Also present was a fear of being unable to complete the tasks, of making mistakes, and of not being able to speak Finnish in the seminar. According to the data, perfectionism and fear of making mistakes bothered the participants for a long time until they learned that they were allowed to make mistakes. Thus, they learned to study and to learn at the university in a relaxed atmosphere. The interviewees never reported feeling guilt towards their family for going to college when their family members were unable to achieve the same goal, as Covarrubias et al. (2015) reported in their study.

According to these categories, the links that emerged to combine the three main categories - academic environment, academic performance, and academic well-being - can best be explained by functioning and a sense of belonging. The three categories are interrelated. This means that a supportive and encouraging climate in an academic environment can positively affect performance and well-being. Positive feelings of well-being, such as happiness, friendship, and encouraging thoughts, affect the quality of performance. Highquality performance can, again, influence good feelings, valued involvement, and positive perspectives of the students towards the academic environment.

In this study, the sense of belonging referred to the academic environment with the subcategories of academic language, institutional norms, and academic skills among academic learners; it also referred to academic performance, in which a strong relationship between selfefficacy and persistence can be seen. Well-being is expressed in emotions such as pride, happiness, helplessness, fear, stress, friendship, interactions, making decisions and planning, and personal growth in a new environment. This sense of belonging and the status they have achieved is something that interviewees want to maintain. These are among the most essential feelings they expressed. Moreover, the feeling of not being seen differently accelerates the feeling of belonging. They were viewed just like other Finnish students, which gave them a feeling of belonging. This feeling of belonging motivated them to do more to secure their status 
as students and their academic success and led to valued involvement in their study at the university.

As a graduate-to-be seeking to achieve academic goals, individuals work hard and persistently, as giving up is not an option. I call this concept "functioning." This functioning includes all activities and actions related to strategies to overcome academic challenges, in the sense that it is vital to understand the ambition and goals and the field of study one has chosen and to achieve academic and social potentials. This functioning is motivated by the aspiration to have a better life and a good career, and the ability to participate in working and professional life. The desire to be successful personally, but not forgetting to be a good role model for other students with immigrant backgrounds and one's community, makes them more responsible, functioning, and capable. Students must want to function. That is, they must take responsibility for themselves, show perseverance, and work harder and longer than others to belong and meet the requirements, which are the same for all. They are proud to be FGMFSs, and they feel even more responsibility to be successful.

In conclusion, the results of this functioning lead to belonging, which create a circular process in the academic success of these students. That is why the two concepts-a sense of belonging ( $\mathrm{sb}$ ) and functioning (f) - are interdependent. Overall, if you feel that you belong, then you will be functional, and when you are functional, you feel that you belong $[(\mathrm{sb} \Rightarrow \mathrm{f}) \Lambda$ $(\mathrm{f} \Rightarrow \mathrm{sb}) \equiv \mathrm{sb} \Leftrightarrow \mathrm{f}]$.

The results of this study agree with those of previous research in which the feeling of belonging has demonstrated positive effects on the intention to persist (Hausmann et al., 2007); on belonging and identification to reduce retention (Hoffmann et al., 2002); on academic selfefficacy; on intrinsic motivation and task value; on the promotion of student participation (Freeman et al., 2007); sense of belonging as a significant predictor of self-reported metacognitive and academic time management strategies (Won et al., 2018) and on belonging, familiarity, acceptance, and a sense of justice (Teng et al., 2020).

\section{Conclusion}

In this article, based on the study of 15 FGMFSs, the recollections participants on their experiences and perceptions in higher education in Finland were described and analyzed. The experiences and perceptions were classified into three main categories: academic environment, academic performance, and academic well-being. These factors were crucial for the participants' successful studies, according to the information they provided. The three categories help to understand what these students experienced when they entered the university and began their studies, what their strengths were, what challenges they faced, the strategies they employed to address those challenges, and what led to their success.

Based on the GT approach, in which a link between the categories is sought, in this study, the links between the three identified categories are best described as "sense of belonging" and "functioning." The sense of belonging is an important factor in the time spent at the university, as it was for the interviewees in this study. A sense of belonging is important for FGMFSs' status and their position in their families and society. The sense of belonging can be strengthened by a valued involvement, where they can see themselves as leaders of their self-growth as academic learners in the pursuit of achieving their goals. It gives them the strength of "functioning." This functioning is reflected in their persistence and self-efficacy, which we can also be referred to as "very hard working." The perception of the different situations results from the interactions between their individual experiences and the academic context in which they took place. At first, their experiences are perceived through their naive perspective, but, after a while, they perceive the values on which the academic environment is based. In other words, at first, they do not "see" how everything works. They learn more and more and find better ways to cope and to act efficiently in their studies and their learning. As a 
result, their perceptions change and, therefore, both the sense of belonging and the functioning complement each other.

The results also indicate that additional university activities and support programs are needed to help more students become successful, especially those with this background, in their academic careers. The results of this study can help educators and administrators better understand the vital role these two concepts play in the education of FGMFSs and what individual steps can be taken to improve the education and services provided to them. This may consist of considering and possibly developing further academic, social, and cultural programs to strengthen the sense of belonging and functioning at the university for this group of students. The following points can be mentioned as practical implications of this study on a micro (teachers and professors) and a macro level (administration):

Micro level:

- Providing support by teachers and professors through active inquiry when needed

- Creating situations in the classroom in which students' previous knowledge and experiences can be presented concerning cultural backgrounds

- Promoting friendships and friendly peer relations among students to prevent loneliness

- Using, supporting and encouraging group work and cooperation actively

- Strengthening self-efficacy through motivation and recognition

- Supporting and promoting effective individual working habits

- Strengthening and enhancing personal and informal communication, discourse and meetings between teachers and students

Macro level:

- Offering enough support at the beginning of the study program for students to enhance understanding the nature of academic environments and to organize studies properly

- Organizing and offering courses for academic writing

- Organizing informal activities to create opportunities to make friends and strengthen peer relations in the study contexts

- Developing and offering intercultural programs, seminars, and courses also in cooperation with students

- Appreciating students' cultural and other knowledge and experiences in developing the curricula.

\section{Funding Details}

The authors received no financial support for the research, authorship, and/or publication of this article.

\section{Disclosure Statement}

The authors reported no potential conflict of interest 


\section{References}

Airas, M., Delahunty, D., Laitinen, M., Shemsedini, G., Stenberg, H., Saarilammi, M., Sarparanta, T., Vuori, H., \& Väätäinen, H. (2019). Background matters. Students with an immigrant background in higher education. National Centre for Educational Assessment. https://karvi.fi/app/uploads/2019/11/KARVI_2219.pdf

Aldiabat, K. M., \& Le Navenec, C. (2018). Data saturation: The mysterious step in grounded theory method. Qualitative Report, 23(1), 245-261. https://nsuworks.nova.edu/tqr/vol23/iss1/18

Amos, A.E. (2010). Perceptions of the persistent: Academic experiences of first generation community college students (Publication NO. 3427462) [Doctoral dissertation, Capella University]. ProQuest LLC.

Baum, S., \& Flores, S. M. (2011). Higher education and children in immigrant families. The Future of Children, 21(1), 171-193. http://www.jstor.org/stable/41229016

Berggren, J., Torpsten, A.-C., \& Berggren, U. J. (2020). Education is my passport: Experiences of institutional obstacles among immigrant youth in the Swedish upper secondary educational system. Journal of Youth Studies, 6(23), 1-15. https://doi.org/ 10.1080/13676261.2020.1728239

Biggs, J. B. (1989). Approaches to the enhancement of tertiary teaching. Higher Education Research \& Development, 8(1), 7-25. https://doi.org/10.1080/0729436890080102

Bonin, H. (2017). The potential economic benefits of education of migrants in the EU (Report No. 31). IZA Institute for Labour Economics. http://ftp.iza.org/report_pdfs/iza_ report_75.pdf

Bui, V. (2002). First-generation college students at a four-year university: Background characteristics, reasons for pursuing higher education, and first-year experiences. College Student Journal, 36(1), 3.

Castillo-Montoya, M. (2019). Professors' pedagogical strategies for teaching through diversity. Review of Higher Education, 42(Suppl. 2019), 199-226. https://doi.org/10.1353/rhe.2019.0050

Charmaz, K. (2006). Constructing grounded theory. A practical guide through qualitative analysis. Sage publications.

Chemers, M. M., Hu, L. T., \& Garcia, B. F. (2001). Academic self-efficacy and first-year college student performance and adjustment. Journal of Educational Psychology, 93(1), 55-64. https://doi.org/10.1037//0022-0663.93.1.55

Clarke, A. E. (2009). From grounded theory to situational analysis. What's new? Why? How? In J. M. Morse, P. N. Stern, J. Corbin, B. Bowers, K. Charmaz, \& A. E. Clarke (Eds.), Developing grounded theory: The second generation (pp. 194-235). Left Coast Press.

Cobo-Rendon, R., Perez-Villalobos, M. V., Paez-Rovira, D., \& Gracia-Leiva, M. (2020). A longitudinal study: Affective well-being, psychological wellbeing, self-efficacy and academic performance among first-year undergraduate students. Scandinavian Journal of Psychology, 61, 518-526. https://doi.org/ 10.1111/sjop.12618

Conway, K. M. (2009). Exploring persistence of immigrant and native students in an urban community college. The Review of Higher Education Spring, 32(3), 321-352. https//doi.org/ 10.1353/rhe.0.0059

Corbin, J., \& Strauss, A. (2007). Basics of qualitative research: Techniques and procedures for developing grounded theory (3rd ed.). Sage publications.

Covarrubias, R., Romero, A., \& Trivelli, M. (2015). Family achievement guilt and mental wellbeing of college students. Journal of Child \& Family Studies, 24(7), 2031-2037. https://doi.org/10.1007/s10826-014-0003-8

Creswell, J. W., \& Poth, C. N. (2018). Qualitative inquiry and research design: Choosing among five approaches (4th ed.). Sage Publications. 
DeFreitas, S. C., \& Rinn, A. (2013). Academic achievement in first generation college students: The role of academic self-concept. Journal of the Scholarship of Teaching \& Learning, 13(1), 57-67.

Delima, D. G. (2019). Making a case for a funds of knowledge approach to teaching and learning for first-generation college students. College Teaching, 67(4), 205-209. https://doi.org/10.1080/87567555.2019.1630355

Demetriou, C., Meece, J., Eaker-Rich, D., \& Powell, C. (2017). The activities, roles, and relationships of successful first-generation college students. Journal of College Student Development, 58(1), 19-36. https://doi.org/10.1353/csd.2017.0001

Dennis, J. M., Phinney, J. S., \& Chuateco, L. I. (2005). The role of motivation, parental support, and peer support in the academic success of ethnic minority first-generation college students. Journal of College Student Development, 46(3), 223-236. https://doi.org/ $10.1353 / \mathrm{csd} .2005 .0023$

Diener, E. (2006). Guidelines for national indicators of subjective well-being and ill-being. Applied Research in Quality of Life, 1, 151-157. https://doi-org.libproxy.tuni.fi/10. 1007/s11482-006-9007-x

Dotson, R. (2016). Goal setting to increase student academic performance. Journal of School Administration Research \& Development, 1(1). 44-46.

Edman, J. L., \& Brazil, B. (2007). Perceptions of campus climate, academic efficacy and academic success among community college students: An ethnic comparison. Social Psychology of Education, 12, 371-383. https://doi.org/ 10.1007/s11218-008-9082-y

Forrest Cataldi, E. F., Bennett, C. T., \& Chen, X. (2018). First-generation students college access, persistence, and postbachelor's outcomes (NCES 2018-421). U.S. Department of Education. National Center for Education Statistics. https://nces.ed.gov/pubs2018/2018421.pdf

Freeman, T. M., Anderman, L. H., \& Jensen, J. M. (2007). Sense of belonging in college freshmen at the classroom and campus levels. Journal of Experimental Education, 75(3), 203-220. https://doi.org/10.3200/JEXE.75.3.203-220

Glaser, B. G. (2002). Constructivist grounded theory? Forum: Qualitative Social Research, 3(12). https://www.qualitative-research.net/index.php/fqs/article/view/825

Glaser, B. G., \& Strauss, A. L. (1967). The discovery of grounded theory: Strategies for qualitative research. Aldine Transition. http://www.sxf.uevora.pt/wp-content/uploads/ 2013/03/Glaser_1967.pdf

Gräbel, B. F. (2017). The relationship between wellbeing and academic achievement: A systematic review [Master's thesis, University of Twente]. http://essay.utwente.nl /73514/

Hausmann, L. R. M., Schofield, J. W., \& Woods, R. L. (2007). Sense of belonging as a predictor of intentions to persist among African American and white first-year college students. Research in Higher Education, 48(7), 803-839. https://doi.org/10.1007/s11162-0079052-9

Hill, K., Hoffman, D., \& Rex, T. R. (2005). The value of higher education: Individual and social benefits [Report]. Arizona State University's Productivity and Prosperity Project. http://precisionmi.com/precisionmi/Materials/PMILearningMat/ValueFullReport_ final_october2005.pdf

Hoffmann, J., Richmond, J., Morrow, J., \& Salomone, K. (2002). Investigating "sense of belonging" in first-year college students. Journal of College Student Retention Research Theory \& Practice, 4(3), 227-256. https://doi.org/10.2190/DRYC-CXQ9-JQ8V-HT4V

Holt, J. K., \& Winter, L. B. (2018). Improving college outcomes for first-generation students. E-journal of Public Affairs, 7(3). http://www.ejournalofpublicaffairs.org/improvingcollege-outcomes-for-first-generation-students/ 
Holton, J. A., \& Walsh, I. (2017). Classic grounded theory. SAGE Publications.

Horowitz, G. (2017). First-generation college students: How to recognize them and be their ally and advocate. Journal of College Science Teaching, 46(6), 8-9. https://doi.org/10.2505/4/jcst17_046_06_8

Ilett, D. (2019). A critical review of LIS literature on first-generation students. Portal: Libraries and the Academy, 19(1), 177-196. https://doi.org/10.1353/pla.2019.0009

Ives, J., \& Castillo-Montoya, M. (2020). First-generation college students as academic learners: A systematic review. Review of Educational Research, 90(2), 139-178. https://doi.org/10.3102/0034654319899707

Jeynes, W. H. (2003). A meta-analysis: The effects of parental involvement on minority children's academic achievement. Education \& Urban Society, 35(2), 202-218. https://doi.org/10.1177/0013124502239392

Kalalahti, M., Niemi, A. M., Varjo, J., \& Jahnukainen, M. (2020). Diversified transitions and educational equality? Negotiating the transitions of young people with immigrant backgrounds and/or special educational needs. Nordic Studies in Education, 40(1), 3654. https://doi.org/10.23865/nse.v40.2127

Makrooni, G. (2019). Being a first-generation migrant family student in Finland: Perceptions and experiences of the educational journey to higher education. Journal of Ethnic \& Cultural Studies, 6(3), 157-170. http://dx.doi.org/10.29333/ejecs/293

Makrooni, G. (2020). From challenge to empowerment: Cross-cultural experiences and perceptions of first-generation migrant family students. Journal of Ethnic \& Cultural Studies, 7(3), 112-128. http://dx.doi.org/10.29333/ejecs/522

Martin, A. J., \& Marsh, H. W. (2009). Academic resilience and academic buoyancy: Multidimensional and hierarchical conceptual framing of causes, correlates and cognate constructs. Oxford Review of Education, 35(3), 353-370. https://doi.org/10.1080/ 03054980902934639

Meeuwisse, M., Severiens, S. E., \& Born, M. P. H. (2010). Learning environment, interaction, sense of belonging and study success in ethnically diverse student groups. Research in Higher Education, 51, 528-545. https://doi.org/10.1007/s11162-010-9168-1

Mendez, J. J., \& Baumann, S. (2018). From migrant farmworkers to first generation Latina/o students: Factors predicting college outcomes for students participating in the college assistance migrant program. Review of Higher Education, 42(1), 173-208. https://doi.org/10.1353/rhe.2018.0037

Moitus, S., Weimer, L., \& Välimaa, J. (2020). Flexible learning pathways in higher education. Finnish Education Evaluation Centre. https://karvi.fi/en/higher-education/thematicand-system-evaluations/unesco-iiep-project-on-flexible-learning-pathways-in-highereducation- $2 /$

Morse, J. M., Barrett, M., Mayan, M., Olson, K., \& Spiers, J. (2002). Verification strategies for establishing reliability and validity in qualitative. International Journal of Qualitative Methods, 1(2), 13-22. https://doi.org/10.1177/160940690200100202

Neto, F., \& Wilks, D. C. (2017). Predictors of psychological adaptation of Cape Verdean students in Portugal. Journal of College Student Development, 58(7), 1087-1100. https://doi.org/10.1353/csd.2017.0085

Paulsrud, B. A., Zilliacus, H., \& Ekberg, L. (2020). Spaces for multilingual education: Language orientations in the national curricula of Sweden and Finland. International Multilingual Research Journal, 14(4), 304-318. https://doi.org/10.1080/19313152.2020.1714158

Pellew, R. (2016). Factors that impact the retention of first-generation college students [Master's thesis, Drexel University]. https://doi.org/10.13140/RG.2.1.1284.7609. 
Quinn, D. E., Cornelius-White, J., MacGregor, C., \& Uribe-Zarain, X. (2019). The success of first-generation college students in a trio student support services program: Application of the theory of margin. Critical Questions in Education, 10(1), 44-64.

Ramos-Sanchez, L., \& Nichols, L. (2007). Self-efficacy of first-generation and non-firstgeneration college students: The relationship with academic performance and college adjustment. Journal of College Counseling, 10(1), 6-18. https://doi.org/10.1002/j.21611882.2007.tb00002.x

Ribeiro, R. (2014). The role of experience in perception. Human Studies, 37, 559-581. https://doi.org/10.1007/s10746-014-9318-0

Rupsiene, L., \& Pranskuniene, R. (2010). The variety of grounded theory: Different versions of the same method or different methods? Social Science / Socialiniai Mokslai, 4(70), $7-20$.

Schwartz, S. J., Waterman, A. S., Umaña-Taylor, A. J., Lee, R. M., Kim, S. Y., Vazsonyi, A. T., Huynh, Q. L., Whitbourne, S. K., Park, I. J. K., Hudson, M., Zamboanga, B. L., Bersamin, M. M., \& and Williams, M. K. (2013). Acculturation and well-being among college students from immigrant families. Journal of Clinical Psychology, 69(4), 298318. https://doi.org/10.1002/jclp. 21847

Stebleton, M. J., \& Soria, K. M. (2012). Breaking down barriers: Academic obstacles of firstgeneration students at research universities. Learning Assistance Review, 17(2). https://files.eric.ed.gov/fulltext/EJ1002281.pdf

Strauss, A., \& Corbin, J. (1994). Grounded theory methodology: An overview. In K. D. Norman \& S. L. Y. Vannaeds (Eds.), Handbook of qualitative research (pp. 22-23). SAGE Publications.

Teng, M. Y., Brown, M. L., Jarus, T., \& Bulk, L. Y. (2020). How does a sense of belonging develop in post-secondary? A conceptual belonging in academia model (BAM) from sighted perspectives. Research in Education, 108(1), 80-103. https://doi.org/ $10.1177 / 0034523719882455$

Tinto, V. (1993). Leaving college: Rethinking the causes and cures of student attrition (2nd rev. ed.). The University of Chicago Press.

Tinto, V. (1998). Colleges as communities: Taking research on student persistence seriously. Review of Higher Education, 21(2), 167-177. https://muse.jhu.edu/article/30046/ summary

United Nations. (2017). Sustainable development goals report. https://unstats.un.org/sdgs/ report/2017/

Vuong, M., Brown-Welty, S., \& Tracz, S. (2010). The effects of self-efficacy on academic success of first-generation college sophomore students. Journal of College Student Development, 51(1), 50-64. https://doi.org/10.1353/csd.0.0109

Won, S., Wolters, C.A., \& Mueller, S.A. (2018). Sense of belonging and self-regulated learning: Testing achievement goals as mediators. Journal of Experimental Education, 86(3), 402-418. https://doi.org/10.1080/00220973.2016.1277337

Zilliacus, H., Holm, G., \& Sahlström, F. (2017). Taking steps towards institutionalising multicultural education - The national curriculum of Finland. Multicultural Education Review, 9(4), 231-248. https://doi.org/10.1080/2005615X.2017.1383810

Zimmermann, B. J. (2000). Self-efficacy: An essential motive to learn. Contemporary Educational Psychology, 25(1), 82-91. https://doi.org/10.1006/ceps.1999.1016 


\section{Notes on Contributors}

Golaleh Makrooni is a $\mathrm{PhD}$ researcher at the Faculty of Education and Culture at Tampere University, Finland and currently lecturer and coordinator for an online course at the Finnish University Partnership for International Development (UniPID, Finland). She holds a MA in History and Philosophy of Education and a BS in Civil Engineering. Her research interests are in higher education, adult and vocational education, teacher education, education and migration, diversity, and cross-cultural studies.

Eero Ropo, Ph.D, is a professor of education (emeritus, 2020-), specializing in teacher education and learning research, since 1996 at the Faculty of Education and Culture, Tampere University, Finland. He has made his doctoral degree at the University of Tampere in 1984. Since then he has acted as a researcher, lecturer, associate professor and professor in general education, primary teacher education, and secondary teacher education. He has been as a visiting scholar at the University of Pittsburgh, Texas Tech University and Vanderbilt University $(1984-5,1996,1997)$ and professor at the Nord University, Norway (2016-2019). During the last ten years Ropo has actively been involved in the international education, being head of the MA program in teacher education in Indonesia and TE programs in Argentina and Brasil. Ropo pursues research on teacher education, narrativity in learning and identity, and curriculum theory. E-mail: Eero.ropo@tuni.fi 